\title{
Uma Arquitetura Pedagógica baseada na diversidade de estratégias de ensino: proposta para o ensino técnico em informática
}

\author{
Éder Marinho de Oliveira ${ }^{1}$ \\ edermarinho@brturbo.com.br \\ Liliana M. Passerino ${ }^{2}$ \\ liliana@feevale.br \\ ${ }^{1}$ Licenciatura em Computação - Centro Universitário Feevale - NH - RS - Brasil \\ ${ }^{2}$ Licenciatura em Computação - Centro Universitário Feevale \\ Resumo: $O$ nível de ensino técnico no Brasil se caracteriza por não \\ apresentar muitas pesquisas e discussões em torno de métodos e propostas \\ que visem um acréscimo de qualidade do ensino em questão. Neste cenário, o \\ presente artigo apresenta uma proposta de arquitetura pedagógica para o \\ ensino técnico de informática, baseado na diversidade de estratégias de \\ ensino. A respectiva proposta foi inspirada nos conceitos de Engenharia \\ Pedagógica e baseada no Método MISA (Méthode d'Ingénierie d'un Systéme \\ d'Apprentissage) que representa um método de suporte para a concepção de \\ um sistema de aprendizagem.
}

palavras-chave: engenharia pedagógica, ensino técnico, sistema de aprendizagem.

\section{A Pedagogical Architecture based on the diversity of teaching strategies: proposals to a technical teaching of computer science}

\begin{abstract}
The level of the technical teaching in Brazil is characterized by the lack of researches and discussions about methods and proposals which aim an increase of the quality in this process. In fact, this article presents a proposal of pedagogical architecture to a technical teaching of computer science based on the diversity of teaching strategies. The respective issue was inspired in the Concepts of Pedagogical Engineering and based on the MISA Method (Méthod d'Ingéniere d'un Systéme d'Apprentissage) which represents a method of support to the conception of a learning system.
\end{abstract}

keywords: pedagogical architecture, technical teaching, learning system.

\section{Introdução}

O presente artigo é uma proposta de arquitetura pedagógica para o ensino técnico que teve como origem a prática educativa desenvolvida numa turma do primeiro ano de um curso técnico em informática realizada numa escola do ensino privado na região do Vale dos Sinos (RS), durante o primeiro semestre de 2006. O contexto da respectiva prática foi a disciplina de Introdução a Computação, que aborda com maior ênfase os conteúdos relacionados à arquitetura de computadores. A mesma constitui-se basicamente em estudos do hardware de um computador, bem como aspectos relacionados à teoria computacional. 
A partir da reforma na educação profissional de nível técnico, determinada pela edição do Decreto Federal n. ${ }^{\circ}$ 2208/97, que desintegrou o curso técnico do Ensino Médio, tornou-se freqüente a formação de turmas de alunos bastante heterogêneas, em diversos sentidos. Alunos com idades, experiências, ocupações e expectativas diferentes compõem hoje as turmas de cursos técnicos. Assim, alunos com perfis bastante distintos dividem hoje os mesmos espaços, recursos e ambientes de ensino. Dessa forma, cabe ao professor conduzir as aulas em cada disciplina a partir do contexto educativo identificado. Esta ação pedagógica do professor é uma das principais variáveis que contribuem para o aprendizado de cada aluno e para a satisfação e a motivação de cada indivíduo também. A partir da identificação da heterogeneidade de uma turma, como decidir qual estratégia de ensino adotar? Qual recurso utilizar? Que métodos trarão mais vantagens? Qual a melhor forma de avaliar? São questões pertinentes à prática em questão e que levam a uma reflexão em torno de uma "arquitetura pedagógica baseada na diversidade de estratégias de ensino", tendo como estudo de caso a disciplina de Introdução à Computação de um curso técnico em informática.

\section{Estudos Preliminares}

O objetivo deste item é expor alguns estudos preliminares que foram realizados e que serviram de base para fundamentar a proposta deste artigo. Serão tratados neste, os estudos referentes à prática do construtivismo, os tipos de aprendizagem, e a avaliação formativa. Muitas instituições de ensino estão inseridas atualmente, numa proposta pedagógica construtivista. Para Vygotsky (1991), o desenvolvimento do indivíduo acontece no convívio social, ou seja, no contato e na interação com outros indivíduos. A prática do trabalho em grupo ou momentos que oportunizem a troca de experiências e de conhecimentos entre os colegas aprendizes são estratégias que vem de encontro à ótica da pedagogia construtivista e trazem vantagens na prática do ensino da computação. Pode parecer estranho, mas sob esta ótica construtivista, um dos problemas em questão aqui, deixa de ser problema para se transformar em vantagem significativa no que diz respeito ao processo de aprendizagem. A troca de experiências e de opiniões entre os alunos, seja num trabalho em grupo ou numa discussão maior, é fundamental para que eles avancem em suas concepções sobre o objeto de estudo. A heterogeneidade de uma turma, antes posta como dificuldade, neste caso enriquece e apóia o trabalho do professor, uma vez que os alunos pensam de forma distinta.

Mesmo num contexto em que o domínio de conteúdo previsto no plano de ensino tenha predominantemente aspectos teóricos e conceitos a serem trabalhados pelo educador, práticas e simulações que visem comprovar e reforçar a teoria estudada são metodologias fundamentais sob uma ótica construtivista. Piaget (1990) ao formular a Epistemologia Genética, que analisa a evolução do raciocínio humano, do nascimento à maturidade do indivíduo, definiu um modelo com base na interação do sujeito - objeto. De acordo com este modelo, o conhecimento não está no sujeito nem no objeto, mas sim na interação entre ambos (Becker, 2002).

A partir do conceito de aprendizagem construtivista, Zabala (1998) classificou a aprendizagem em diversos tipos ou níveis, tendo como base desta classificação três grandes pilares: conhecimentos, habilidades e valores. Conhecer os diferentes tipos de aprendizagem permite ao educador, ter uma visão mais ampla e completa no que diz respeito ao processo de aprendizado de seus alunos e o ajuda a proporcionar momentos e atividades em sala de aula que visem uma formação mais integra de seus aprendizes.

O primeiro tipo de aprendizagem definido é a aprendizagem de conteúdos factuais, que representa a informação dos fatos, acontecimentos, situações, dados e 
fenômenos. São informações embutidas em folhetos, manuais, cartilhas, palestras entre outros meios. Esse primeiro tipo de aprendizagem é representado pelas informações que se apresenta aos alunos e que podem ser memorizadas e recordadas quando necessário. O segundo tipo de aprendizagem apresentado é a aprendizagem de conceitos e princípios, que implica na compreensão dos significados e na elaboração e construção pessoal de conceitos. Assim é o conhecimento do Sistema binário, da álgebra booleana, do modelo de Von Neumann, entre outros conteúdos trabalhados na disciplina de introdução a computação.

A terceira aprendizagem, segundo a classificação de Zabala (1998), é a aprendizagem de conteúdos procedimentais, representada pelo conjunto de ações ordenadas que abrangem técnicas, regras, procedimentos e métodos dirigidos à realização de um objetivo. Conteúdos procedimentais compreendem a relação entre "saber fazer" e "fazer" ou compreender um conceito e se fazer valer disso numa aplicação prática. A aprendizagem de conteúdos atitudinais finaliza a classificação de aprendizagens proposta por Zabala (1998) e corresponde a uma série de conteúdos que podem ser agrupados em valores, atitudes e normas. Os valores se referem à ética do indivíduo, as atitudes estam relacionadas à forma como o indivíduo atua, ou seja, sua conduta de acordo com seus valores, e as normas se referem ás regras ou padrões de comportamento na qual o indivíduo está inserido enquanto integrante de um grupo social.

A partir do momento em que se estudam os diferentes tipos de aprendizagem, percebe-se que algumas características se distinguem fortemente, o que, por consequiência, exige um método de avaliação diferenciado. Nos últimos anos, têm sido bastante freqüente, estudos sobre o termo "avaliação formativa", que, numa visão mais ampla, objetiva uma ação do professor em busca do desenvolvimento e do crescimento de seus aprendizes. Perrenoud (1999) é um dos autores que abordam este termo, com bastante propriedade. Para ele a avaliação formativa ajuda o aluno a aprender e a se desenvolver, leva em consideração a regulamentação das aprendizagens e do desenvolvimento no sentido de um projeto educativo. O conceito de avaliação formativa se opõem ao conceito de avaliação somativa (tradicional), pois enfatiza a avaliação do processo e não do produto. A regulação da aprendizagem, especificada por Perrenoud (1999), conta com a participação do avaliado, tendo como foco desta abordagem a autoavaliação.

A interatividade constitui-se num elemento importante da avaliação formativa que, através do diálogo, possibilita um processo de humanização tornando o avaliado consciente do seu próprio desenvolvimento. A avaliação formativa está direcionada a uma aprendizagem atitudinal, pois prima pelos princípios éticos ao contrário do processo punitivo e excludente da avaliação tradicional. A avaliação formativa pode se dar antes de desencadear o processo de ensino-aprendizagem, uma vez que, através da auto-avaliação, do autocontrole, da meta-cognição e da prática reflexiva, é possível diagnosticar a situação dos alunos e, a partir daí, tomar as decisões em relação ao curso do processo. Pode se dar também, durante o processo de ensino-aprendizagem, através da interação contínua entre avaliador e avaliados, proporcionando ressignificações e reajustamentos através das interpretações frente aos erros e acertos dos alunos. Também pode se dar no final de um processo, possibilitando uma reorganização das atividades e das estratégias de ensino frente as diferentes necessidades dos indivíduos.

Contudo, a diversificação na utilização de instrumentos de ensino (provas, práticas, seminários e questionários) é importante, pois nenhum é suficientemente fidedigno e fiável. Devem ser considerados apenas como meios de recolha de 
informações, as quais servem de base para todo processo de avaliação dita como formativa. Esta avaliação pretendida é interna ao processo de ensino-aprendizagem e torna o aluno protagonista da sua aprendizagem.

Essa diversificação de instrumentos de ensino, idealizada na avaliação formativa, não deve ficar apenas no âmbito avaliativo. Deve extrapolar as barreiras da sala de aula e atingir a iniciativa dos educadores, os recursos das instituições, os estudos dos coordenadores e todas as frentes que de alguma forma influenciam na aprendizagem dos alunos. A esse processo, que caminha no âmbito geral da educação, dá-se o nome de Engenharia Pedagógica (EP). É justamente esse o assunto a ser discutido a seguir.

\title{
3. Engenharia Pedagógica
}

O termo "Engenharia Pedagógica" (EP) é ainda pouco discutido, uma vez que são poucos os materiais encontrados a esse respeito. Por outro lado, Paquette (2002) aborda este assunto com bastante profundidade. EP constitui-se numa área de conhecimento que trata de questões relacionadas à formação e, como tal, pode também ser definida como engenharia da formação.

\begin{abstract}
“... é um conjunto de princípios, de processos ou de tarefas que permitem definir o conteúdo de uma formação por meio de uma identificação estrutural de conhecimentos e de competências visadas, de realizar um cenário pedagógico de atividades de um curso, definindo o contexto de utilização e a estrutura dos materiais de aprendizagem..." (Gamez, 2004 p. 39).
\end{abstract}

A Engenharia Pedagógica caracteriza-se por uma ação muitas vezes complexa de se implementar, pois se refere a uma abordagem global de todo o processo de ensinoaprendizagem de uma determinada prática pedagógica. São muitos os aspectos relacionados a essa abordagem global. Inicialmente se faz necessário uma análise do perfil dos aprendizes envolvidos, assim como dos aspectos especificados no plano de ensino do curso em questão (objetivos, metodologia e conteúdos). Nesse contexto também tornam-se relevantes aspectos externos ao ambiente escolar, nos quais se enquadram uma análise do mercado de trabalho e da situação social, política e econômica da região, ou das regiões, em que os alunos em questão estão situados, principalmente quando se trata de cursos técnicos ou de qualificação profissional.

Um levantamento dos recursos necessários é parte integrante de um projeto de EP e, como tal, traz junto à necessidade de se analisar a viabilidade financeira junto à instituição de ensino, tanto em relação à aquisição de novos recursos, quanto em relação à realização de passeios, visitas de estudos, práticas em laboratório e outras estratégias do gênero. A formação da equipe que se responsabilizará pela prática de ensino, assim como as atribuições de cada membro desta, deve ser foco de avaliação também. Por fim, as estratégias pedagógicas se caracterizam em um dos principais aspectos de um processo de Engenharia Pedagógica. A busca por um ensino de qualidade é, sem dúvida, o grande objetivo de um projeto de EP e as estratégias pedagógicas escolhidas estão diretamente associadas a esse fator.

Quando já se tem definido um plano de ensino, um ambiente de estudo e um histórico de práticas realizadas sob estes dois elementos, e, deseja-se iniciar um projeto de Engenharia Pedagógica, se está na verdade realizando um processo de Reengenharia. É importante que a Reengenharia aconteça de forma muita cautelosa, pois todo processo de mudança deve ser bem conduzido para que se atinja o grau de sucesso esperado. Atualmente, muitas escolas se encontram em processo de transformações e adaptações, seja devido às teorias educacionais contemporâneas ou à revolução tecnológica que 
influencia diretamente a área da educação. É nessa "onda" de transformações e adaptações que a Reengenharia "pega carona" e surge como elemento capaz de impulsionar os educadores na luta por um ensino de maior qualidade. A seguir serão apresentadas algumas definições e discussões a respeito de Reengenharia e Reengenharia Pedagógica (RP).

\subsection{Reengenharia}

A Reengenharia é na verdade uma técnica que nasceu no âmbito da ciência da Administração, entretanto Gamez (2004) contextualizou o seu desenvolvimento ao tentar "compreender quais são as lições que dela se pode retirar, adaptando-a para o âmbito das transformações no contexto educacional" (p26). O termo Reengenharia está associado à reestruturação de tarefas e processos tendo sempre como base um programa de melhoria de qualidade. Michael Hammer, através de seus estudos na década de 80 e 90, constitui-se no autor deste termo, associando-o a obtenção de melhoramentos acentuados na área da administração. Gamez (2004) comenta que segundo Hammer, em seu livro Reengineering the Corporation (1993), a palavra chave na definição de Reengenharia é "processo", que se caracteriza por uma série final completa de atividades que juntas criam valor ao cliente ( $\mathrm{p} 27)$.

O prefixo "Re" remete a expressão "começar de novo", ou seja, começar uma nova Engenharia. A Reengenharia sugere a quebra de regras e de procedimentos dentro de um determinado contexto, proporcionando desta forma reorganizações, readaptações e novas formas de se fazer. Esse fato estimula a criação de novos métodos. Percebe-se então que, a definição de Reengenharia, embora contextualizada na área empresarial, pode ser aplicada a qualquer área que envolva o termo processo. Na educação este termo é muito familiar, tanto que o foco deste trabalho está centrado justamente no "processo" de ensino-aprendizagem.

Percebe-se atualmente, dentro de muitas instituições de ensino do Brasil, não só uma necessidade, mas também diversas iniciativas buscando inovações no que diz respeito à prática educativa. Esse movimento em prol de inovações constitui-se em processos de Reengenharia Educacional. Dos poucos autores que arriscam uma associação do termo Engenharia com Educação, Collis (1996 apud GAMEZ 2004) expõem duas formas de prover Reengenharia Pedagógica. Uma delas é modificar o equilíbrio entre os componentes instrucionais num determinado curso e a outra é mudar, enriquecer ou aprofundar um componente individual. Para Collis, estas são duas considerações capazes de promover uma inovação significativa visando um ganho no que diz respeito à qualidade do ensino em questão. Chaves (1999 apud Gamez 2004), por sua vez, acredita que promover a Reengenharia da educação é "repensar fundamentalmente seus objetivos básicos e reestruturar os processos por meio dos quais tais objetivos devem ser alcançados, com vistas a obter melhorias em indicadores críticos e contemporâneos de desempenho" (p 33).

Shandler (1996) propôs um modelo de transformação do treinamento clássico tradicional das empresas em um modelo de aprendizagem contínua, baseado nos princípios da Reengenharia. $\mathrm{O}$ objetivo era buscar a transformação da atividade de formação profissional através da aplicação de um modelo de Reengenharia Educacional. $\mathrm{Na}$ sua proposta, Shandler inspirou-se no modelo de $6 \mathrm{R}$ 's de "Reengenharia e Transformação Organizacional". Este constitui-se em 6 fases que fornecem "a linguagem para a compreensão dos conceitos subjacentes envolvidos na transformação organizacional e no processo de Reengenharia" (Edosomwan apud Gamez 2004) e que pode ser aplicado em diversos tipos de mudanças, inclusive nas educacionais. 
A primeira fase deste modelo é a fase da Realização. Gamez (2004), trazendo a caracterização para o plano educacional, diz que esta fase consiste em definir o porquê da Reengenharia Pedagógica, o que se pretende com a mudança, seus objetivos e suas razões além de conhecer as iniciativas das outras instituições de ensino concorrentes e analisar os impactos da aplicação de tais transformações. A segunda fase refere-se aos Requisitos, que consiste nas ações que visam a satisfação do cliente e muitas vezes dizem respeito aos princípios e diretrizes do projeto. Repensar caracteriza-se na terceira fase, que exige uma análise bastante profunda de toda a organização (estrutura, sistema, recursos, e processos) da instituição em questão.

A fase seguinte é o Replanejamento, que foca na compreensão do processo e das transformações pretendidas, ou seja, consiste na pontuação dos meios para que se possa repensar o curso e atingir os objetivos através das mudanças. A fase de Reformulação é a próxima etapa e consiste na avaliação e adaptação das transformações propostas a fim de garantir um sucesso maior em sua aplicação. Em outras palavras, esta fase visa minimizar as possíveis falhas ou erros das modificações propostas, quando na sua aplicação. É nessa fase que o processo de Reengenharia Pedagógica toma forma, pois consiste no desenvolvimento e concepção do curso em questão. Por fim a Reavaliação surge como complemento de todo o modelo, pois é nessa fase que se efetuam os testes e ensaios a fim de se avaliar seus resultados.

Retomando um pouco a idéia de Engenharia Pedagógica, Paquette (2002) expõem a dificuldade em se implementar um processo de EP atualmente, uma vez que a maioria dos métodos tradicionais de desenho pedagógico disponível foi elaborada em meados dos anos 70. A partir deste fato, Paquette junto com sua equipe, em 1992, propõem a concepção de um novo método de EP, mais condizente com as necessidades dos tempos atuais. Um método de suporte á análise, concepção, realização e planejamento de práticas educativas. Trata-se do método MISA, cujas idéias principais são apresentadas a seguir.

\subsection{Método MISA}

MISA (Méthode d'Ingénierie d'un Systéme d'Apprentissage ${ }^{1}$ ) é um método de suporte a concepção de um sistema de aprendizagem, que estabelece a relação entre o desenho pedagógico, a engenharia de software e a engenharia cognitiva e, desta relação, tira algumas de suas propriedades (Paquette 2002, apud Gamez 2004). Este método caracteriza-se por agrupar uma série de objetos pedagógicos, tarefas e princípios de funcionamento organizados, a fim de servir de base na construção de um sistema de aprendizagem. Oferece suporte para cento e oitenta e cinco tarefas e processos, sendo trinta e cinco consideradas como principais e cento e cinqüenta secundárias. Teve como base de desenvolvimento pesquisas no âmbito da Engenharia Pedagógica e da experiência adquirida ao longo da execução de projetos de desenvolvimento de produtos e de serviços de formação nas quais esse método foi aplicado. Todo estudo de desenvolvimento deste método foi conduzido pelo Centro de Pesquisa LICEF, da TéleUniversité no Québec.

Assim como ocorre no Método de 6R's, apresentado anteriormente, o MISA também se baseia em 6 processos ou fases principais. O primeiro se constitui na definição do problema de formação e o segundo na proposta de solução preliminar. Em seguida surge a concepção da arquitetura pedagógica. $\mathrm{O}$ quarto processo caracteriza-se pela concepção dos materiais pedagógicos, enquanto que o quinto processo constitui-se na validação dos materiais. Por fim, surge o planejamento da difusão do sistema de aprendizagem. 
A progressão por entre estas seis fases pode-se dar em quatro dimensões, segundo Gamez (2004). A "modelagem de conhecimentos", que aborda os diferentes tipos de conhecimento e as relações entre eles, permitindo uma escolha de atividades mais condizentes com as reais necessidades. A "concepção pedagógica", que através do software $\mathrm{ADISA}^{2}$, que automatiza as operações de concepção para as unidades de aprendizagem. O "Planejamento da mídia" caracteriza-se pela terceira dimensão, que permite um design completo das diversas mídias que formarão o sistema de aprendizagem, ressaltando que o foco do método MISA é a construção de sistemas de aprendizagem voltados para a Educação a Distância (EAD), embora possa ser adaptado para outras realidades, como no presente trabalho. O "Planejamento da difusão" finaliza o conjunto das quatro dimensões que envolvem a progressão das fases do método MISA. Corresponde as questões de infra-estruturas necessárias a sua difusão e as tarefas de gestão da formação.

O método MISA pode ser modelado com o auxílio de um editor de modelos MOT (Modélisation par objects typés). Paquette (2002) também apresenta alguns conceitos quando no desenvolvimento deste método. Conceitos que podem ser comparados como sendo os quatro pilares bases de sustentação do método MISA. São eles: conhecimentos, competências, habilidades e elementos de documentação.

O conhecimento segundo Paquette, constitui-se em dois grupos chamados de abstratos e concretos. O tipo abstrato por sua vez divide-se em três outros tipos: conceitos, procedimentos e princípios. Estes correspondem aos tipos de aprendizagem já discutidos nos estudos preliminares. O tipo concreto, também pode ser chamado de fato que corresponde respectivamente à aprendizagem factual também abordada anteriormente. No sistema $\mathrm{MOT}^{3}$, os diferentes tipos de conhecimentos são representados de maneira integrada por esquemas que estabelecem diversos tipos de ligações. Outro conceito abordado pelo respectivo autor é o de "competência", e a define como sendo "a capacidade atual ou visada, de um grupo ou de um indivíduo, de exercer uma habilidade, em relação a um ou mais conhecimentos, em um certo contexto" (PAQUETTE, 2002). Em outras palavras, competência é a relação entre conhecimentos, habilidades e atitudes.

Já a "habilidade" é definida como sendo "meta-conhecimentos" que permitem a um indivíduo tratar os fatos ou os conhecimentos de diferentes domínios, para os perceber, memorizar, aplicar, analisar, sintetizar, avaliar ou ainda os utilizar em uma ação. Por fim, apresenta um conceito de "elementos de documentação" que, inspirado nos métodos de Engenharia de Software, constitui o produto base do método MISA. Certos elementos são "modelos gráficos que resultam de uma engenharia de conhecimentos", enquanto que outros elementos caracterizam-se por fichas comentadas que descrevem os componentes do futuro sistema de aprendizagem e suas propriedades.

\section{Estudo de Caso: A proposta de Engenharia Pedagógica}

Propõe-se como ação inicial do processo de Engenharia Pedagógica, uma análise a respeito do perfil dos alunos, do plano de ensino do curso e de outros aspectos relevantes como o mercado de trabalho e a situação econômica e cultural da região. $\mathrm{O}$ resultado desta primeira análise é exposto no quadro 1 a seguir, que caracteriza-se num "elemento de documentação", componente integrante de uma Engenharia Pedagógica. 


\begin{tabular}{|l|l|}
\hline Perfil dos Alunos & Plano de Ensino \\
\hline Quantidade de alunos: 15 & Competências e habilidades pretendidas: \\
Idade: de 15 à 40 anos & - Corrigir eventuais problemas de hardware; \\
Alunos que tem atividade profissional: 12 & - Realizar montagens de \\
Alunos que não concluíram ensino médio: & Microcopmputadores; \\
2 & - Diagnosticar motivos de falhas; \\
Algumas atividades profissionais: & - Interpretar manuais; \\
- Topógrafo; & - Identificar tecnologias envolvidas; \\
- Segurança; & - Compreender termos técnicos. \\
\cline { 2 - 2 } - Comerciante; & Mercado de trabalho \\
\cline { 2 - 2 } - Assistente administrativo; & - Informática em crescimento na região; \\
- Vendedor; & - Pouca mão de obra "qualificada"; \\
- Auxiliar de impressão; & - Região com foco no calçado; \\
Algumas Expectativas com o curso: & - Calçado em crise. \\
- Trabalhar na área de suporte técnico; & \\
\cline { 2 - 2 } - Trabalhar ná área de programação; & Situação Econômica dos Alunos \\
\cline { 2 - 2 } - Apenas aprimorar conhecimentos; & - Média; \\
- Melhores oportunidades de trabalho; & - Média baixa. \\
Alunos sem computador em casa: 4; & \\
Alunos com internet em casa: 7; & \\
Conhecimentos prévios de informática: & \\
- Muito bom (3); & \\
- Bom (4); & \\
- Pouco(5); & \\
- Quase nenhum(3). & \\
& \\
&
\end{tabular}

Quadro 1 - Elemento de Documentação da análise inicial

A partir do elemento de documentação acima, segue-se a análise dos recursos e da viabilidade financeira da instituição. Neste sentido, foi percebido na realização de algumas práticas de ensino no decorrer deste trabalho, uma carência no que diz respeito aos recursos de hardware. Nestes, se enquadram desde componentes para estudo e demonstrações até computadores específicos para testes de montagem dos alunos. Apenas o básico destes recursos pode ser oferecido pela instituição de ensino durante a prática pedagógica. Julga-se como ideal neste cenário, a montagem de um laboratório específico de hardware. Um laboratório composto com bancadas de trabalho para realização das práticas de montagem e de manutenção de microcomputadores, competências essas especificadas no plano de ensino do curso. Outro recurso que contribuiria para a prática, mais precisamente no momento de apresentação do seminário desenvolvido em uma das aulas, é um projetor multimídia, que também seria útil nos momentos de exposição teórica.

A concepção da equipe responsável, segundo esta abordagem de EP, deveria ser composta pelo professor propriamente dito, a coordenadora pedagógica e o vice-diretor. A segunda daria o suporte não só em relação à organização do curso em questão e em relação ao acesso aos recursos da instituição, como também ofereceria suporte aos possíveis problemas que poderiam vir a ocorrer durante as aulas. Já o vice-diretor comprometeria-se com a captação de recursos para possíveis investimentos e no suporte à organização de possíveis eventos ou visitas de estudos envolvendo a turma de alunos.

Como uma das ações de finalização da etapa de revisão de uma EP, encontra-se um levantamento das possíveis estratégias de ensino a serem utilizadas no decorrer da prática educativa. Como aspecto norteador do presente artigo, propõe-se uma 
abordagem baseada na diversidade de estratégias de ensino a fim de se atingir o êxito no desenvolvimento das habilidades e competências dos alunos cujos perfis foram analisados em ações anteriores. O levantamento das estratégias de ensino se caracteriza como ação chave nesse processo. No quadro 2 a seguir, encontra-se descrito a relação de algumas estratégias de ensino propostas para a disciplina de Introdução a Computação.

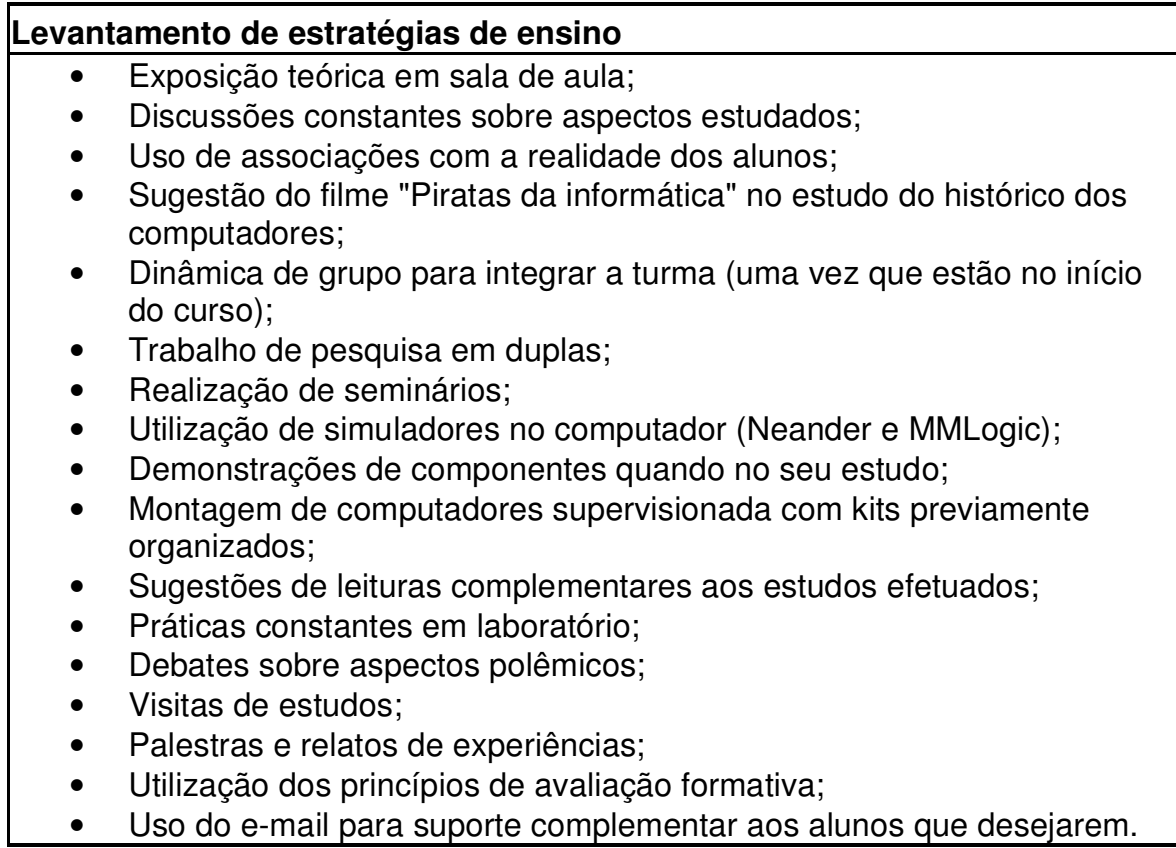

Quadro 2 - Levantamento de algumas estratégias de ensino

A definição destas estratégias de ensino tiveram como base de fundamentação os estudos preliminares realizados (item 2). Muitas surgiram mediante o estudo em torno dos tipos de aprendizagem e dos objetivos que se pretendia alcançar com cada aluno. Cada tipo de aprendizagem requer uma abordagem diferenciada. Uma prática educativa em torno do filme Piratas da Informática, por exemplo, remete a uma aprendizagem de conteúdos factuais, pois contextualiza um acontecimento histórico na evolução dos Sistemas Operacionais, já uma prática em torno da montagem e configuração de um microcomputador remete a uma aprendizagem de conteúdos procedimentais. Os princípios da avaliação formativa também influenciaram na escolha de algumas destas estratégias, bem como as teorias construtivistas aplicadas ao ensino da computação.

\section{Considerações Finais}

O termo "Engenharia Pedagógica" abordado neste trabalho surge como processo capaz de promover mudanças e transformações numa determinada prática de ensino, buscando justamente melhores resultados. Para fundamentar este processo, os estudos preliminares que se caracterizaram pelo construtivismo no ensino da computação, os tipos de aprendizagens, os procedimentos de ensino e a avaliação formativa, serviram de sustentação para uma proposta mais comprometida e voltada para o processo de aprendizagem dos alunos. Além disso, o presente estudo também serviu de motivador para novos trabalhos na área, que caracterizam uma certa continuidade desta prática, constituindo-se no projeto de um sistema de aprendizagem baseado no processo de Engenharia Pedagógica proposto para a prática de ensino aqui relatada. 
Objetiva-se em trabalhos futuros, a aplicação do Método MISA para elaboração de um sistema de aprendizagem baseado no processo de EP aqui apresentado e que sirva de suporte ao ensino técnico de informática. A ênfase pretendida se situará no âmbito da terceira dimensão no progresso das seis fases do método MISA e que se caracteriza pelo "planejamento da mídia". Acredita-se que a construção deste sistema de aprendizagem permitirá aos alunos, entre outras vantagens, a oportunidade de recuperação de conteúdos e a realização de estudos complementares dentro dos tópicos de interesse.

\section{Notas de Texto}

${ }^{1}$ Método de Engenharia de Sistemas de Aprendizagem

${ }^{2}$ ADISA é um software baseado no método MISA (Méthode d'ingénierie d'un Systéme aprentissage), desenvolvido pelo LICEF, que permite trabalhar com quatro tipos de planejamento.

${ }^{3}$ Modelação por Tipos de Objetos.

\section{Referências Bibliográficas}

Becker Fernando. A epistemologia do professor, o cotidiano na escola. $10^{\text {a }}$ Edição. Editora Vozes, Rio de Janeiro - RJ. 2002.

Gamez, L. A Construção da coerência em cenários pedagógicos on-line: uma metodologia para apoiar a transformação de cursos presenciais que migram para a modalidade de educação à distância. Florianópolis, UFSC. 2004.

Paquette, Gilbert. L'Ingénierie pédagogique. Pour construire l'apprentissage en réseau. Sainte-Foy, Québec: Presses de L’Université du Québec, 2002.

Perrenoud, P. Avaliação: da excelência à regulação das aprendizagens - entre duas lógicas. Porto Alegre: Artes Médicas, 1999.

Piaget, J. - Epistemologia genética. Editora Martins Fontes. São Paulo. 1990.

Shandler, Donald. Reengineering the Training Function: How to Align Training with New Corporate Agenda. Delray Beach: St. Lucie Press, 1996.

Vigotsky, L. S. A formação social da mente: o desenvolvimento dos processos psicológicos superiores. $4^{\mathrm{a}}$ Edição. São Paulo: Martins Fontes, 1991.

Zabala, A. A Prática Educativa: Como Ensinar. Porto Alegre. Editora Artes Médicas. 1998. 